\title{
Synthesis and Characterization of Struvite-k Crystals by Agar Gel
}

\author{
Vilas Bhagawat Suryawanshi*, Ravindranath Teniram Chaudhari \\ Physics Research Lab, Shri. V.S. Naik Arts, Commerce and Science College, Raver, India \\ Email: "vbsuryawanshi2007@rediffmail.com
}

Received 26 August 2014; revised 16 September 2014; accepted 16 October 2014

Copyright (C) 2014 by authors and Scientific Research Publishing Inc.

This work is licensed under the Creative Commons Attribution International License (CC BY). http://creativecommons.org/licenses/by/4.0/

(c) (7) Open Access

\begin{abstract}
The phosphate mineral struvite is basically formed in urinary tracks and kidney. One of the analogous compounds of struvite is potassium magnesium phosphate hexahydrate $\left(\mathrm{KMgPO}_{4} \cdot 6 \mathrm{H}_{2} \mathrm{O}\right)$, known as struvite-k crystal and found in animal urinary calculi. In the present investigation, struvite-k crystals were grown by single diffusion and double diffusion techniques in agar gelmedium. The grown crystals were analyzed by optical microscopy, scanning electron microscopy (SEM), fourier transform infrared (FTIR) spectroscopy, X-ray diffraction (XRD), energy dispersive X-ray analysis (EDXA) and thermogravimetric analysis (TGA). Optical microscopy and SEM exhibited the different morphologies. The FTIR spectra revealed the presence of water molecules, stretching and bending vibrations of phosphate $\left.\mathrm{PO}_{4}\right)$ ions. However the powder XRD results from the crystalline nature. Elemental composition in the crystal was obtained by EDXA, while $36.89 \%$ weight loss of water molecules is observed in TGA study.
\end{abstract}

\section{Keywords}

Gel Method, Agar Gel, Struvite-k, Animal Calculi

\section{Introduction}

Urolithiasis is the formation of urinary calculi, known as renal kidney stone, which is one of the serious and debilitating problems in the world [1]. The formations of stones have high supersaturation characteristics, because supersaturation is the driving force for crystal formation and growth [2]. The renal stones are the product of pathological bio mineralization in urinary system which is composed of several components and cannot be contributed to any single factor [3]. Also the chemical composition shows that, growth depends on diet, social class, age, sex of the person and on climatic and environmental conditions [4] [5].

*Corresponding author. 
The urinary crystals are mostly composed of oxalates and phosphates. Among the phosphates, hydroxyapatite [6], carbonate apatite [7] and brushite [8] are the common constituents of calciumphosphate crystals, whereas ammonium magnesium phosphate hexahydrate $\left(\mathrm{NH}_{4} \mathrm{MgPO}_{4} \cdot 6 \mathrm{H}_{2} \mathrm{O}\right)$ known as struvite and magnesium hydrogen phosphate trihydrates $\left(\mathrm{MgHPO}_{4} \cdot 3 \mathrm{H}_{2} \mathrm{O}\right)$, i.e. newberyite, is the common constituents of magnesium phosphates crystals. They are reported in vesicle as well as renal calculi of adults [1] [9] [10] and children [11]-[13]. Of these, newberyite is a very rare crystalline component of urinary calculi [14], while struvite is mostly found in urine [15]. Struvites are also known as infection crystals, because they are form due to urinary tract infections with ureolithic microorganisms in humans and animals [16]-[18]. A series of orthorhombic struvite analogues crystals ( $\mathrm{MM}^{\prime}$ with $\mathrm{M}=\mathrm{Mg}, \mathrm{Zn}, \mathrm{Cd}$ and $\mathrm{M}^{\prime}=\mathrm{K}, \mathrm{Ti}, \mathrm{NH}_{4}, \mathrm{Rb}$ ) were reported due to their biomedical importance [19] [20]. One of the analogous compounds of struvite is potassium magnesium phosphate hexahydrate $\left(\mathrm{KMg}-\mathrm{PO}_{4} \cdot 6 \mathrm{H}_{2} \mathrm{O}\right)$, known as struvite-k crystal [21]-[23], which has been approved (CNMMN-IMA2003) as a new inorganic phosphate mineral [24]. Struvite-k crystals are found in natural minerals as well as in animal urinary calculi [23]-[26].

Gel method is the most versatile and simple technique for growing urinary crystals [27] [28]. In this method, gel acts as an inert and viscous medium for the growth of these crystals [29] [30].

These searchers used different methods to grow analogous of struvite crystals. Ni-Struvite and Zn-Struvite were grown by slow evaporation method [31] [32], by feeding a cottonseed meal and rice straw diet supplemented with MgO, Sun et al. [23] investigated struvite-k crystals in six goats. Zhang et al. [22] observed the dehydration characteristics of synthesized struvite-k at $\mathrm{N}_{2}$ atmosphere. Banks et al. [19] have grown the struvite-k crystals by gel diffusion technique and observed the needle shape crystals; however Chauhan et al. [21] have grown these crystals in silica gel by single diffusion gel techniques and observed different morphologies with changing growth parameters. Till today, the growth of struvite-k crystals in agar gel by single and double diffusion techniques have not been reported.

In the present work, the struvite-k crystals were grown in agar gel at ambient temperature and were characterized by optical microscopy, scanning electron microscopy (SEM), fourier transform infrared (FTIR) spectroscopy, X-ray diffraction (XRD), energy dispersive X-ray analysis (EDXA) and thermogravimetry analysis (TGA).

\section{Experimental}

The growth of struvite-k crystal was carried out by single and double diffusion techniques described by Henisch [33]. The glass test tubes of size $15 \mathrm{~cm}$ in length and $1.8 \mathrm{~cm}$ in diameter and U-tube of size $25 \mathrm{~cm}$ in length and $2.5 \mathrm{~cm}$ in diameter were used as crystallization vessels. Agar gel (Himedia) solution was prepared by mixing ( 0.25 to $1.0 \mathrm{~g}$ ) of agar powder in $100 \mathrm{ml}$ double distilled water at boiling temperature. Potassium dihydrogen phosphate (KDP) (Merck) of concentration (0.5 - 1.0 M) and magnesium acetate (Qualigens) of concentration (0.5 - $1.0 \mathrm{M})$ were used as reactants.

In single diffusion techniques, the agar solution was mixed with the desired concentration and appropriate volume of magnesium acetate. After setting and aging of gel, an aqueous solution of KDP was poured. Initially no precipitation was observed, however nucleations were seen in different regions of the gel within two to eight days. The neutral gel was also employed in this technique.

On reversing the reactants, one reactant KDP was poured with gel, while another reactant, magnesium acetate was poured over set gel. Initially no precipitation was observed, however single nucleation was started growing within a week. Further the growth of nuclei was resulted in the formation of single transparent prismatic type crystal.

However, in double diffusion technique, agar solution was poured in U-tube up to appropriate height and kept for setting. After setting and aging of gel, an aqueous solution of KDP was poured in one limb, while the magnesium acetate in other limb. Both the reactants were diffused slowly through the gel column. Nucleations were starts to grow at the middle of $U$ tube. Growth process took eighty days to complete. The grown crystals were harvested from the gel and washed by double distilled water. Further, grown crystals were characterized by, Optical Microscopy, SEM, FTIR, XRD, EDXA and TGA.

\section{Result and Discussion}

In single diffusion technique, while growing the struvite-k crystals using silica gel, according to Chauhan et al. [21], the formation of Liesegang rings were observed. It was also reported that, the number of rings depends on 
$\mathrm{pH}$ of gel. However in the present study, while growing the struvite-k crystals in agar gel, no Liesegang rings, but heavy nucleation was observed in both single and double diffusion technique. To control the nucleation, different growth parameters such as, concentration of gel, concentration of reactant, aging of gel and volume of reactants was changed, which can be seen in Figure 1 and the optimum condition was established shown in Table 1. Figure 2 shows some transparent dendrites, star, platy, prismatic, and polycrystalline types of crystals grown in single diffusion.

Figure 3(a), shows the growth of struvite-k crystal using magnesium acetate as first reactant, (b) using magnesium acetate as a supernatant and (c) using neutral gel in magnesium acetate as first reactant by single diffusion. Figure 3(a) shows the growth of large numbers of crystals from liquid-gel interface to deep in gel. While in test tube (b), on reversing the reactant, a large nuclei is observed than those observed in test tube (a). This may be due to enough nutrient reached to the nuclei in test tube (b) while in test tube (a) nutrients has been divided, therefore they donot grow in large size. Figure 3(b) shows a big size transparent prismatic type crystal. However Figure 3(c) shows the growth of struvite-k crystals using neutral gel. So many investigators used neutral gel to grow the crystals. According to Bhavsar [34], neutral gel reduce the rate of reaction and control the nucleation, while Patil et al. [35] reported that, the neutral gel increase the size of crystals. However Dalal et al. [36] found that the neutral gel reduced the number of nucleation, but could not change the size of crystals. In the present study while using the neutral gel, it was observed that, the large numbers of nuclei were found to be grown near the gel-gel diffusion interface. Due to heavy nucleation, the size of the grown crystals was not increased as shown in Figure 3(c).

In double diffusion, the crystals were grown at the middle of U tube as shown in Figure 4. The obtained optimum condition for double diffusion was reported in Table 1. While growing the crystals in double diffusion technique, it was found that, the shape and surface morphology of the grown crystals was changed. Dumb-bell shape morphology was observed in double diffusion as shown in Figure 5. Variations in morphology were due to changes in the kind of diffusions of the solvents [37].

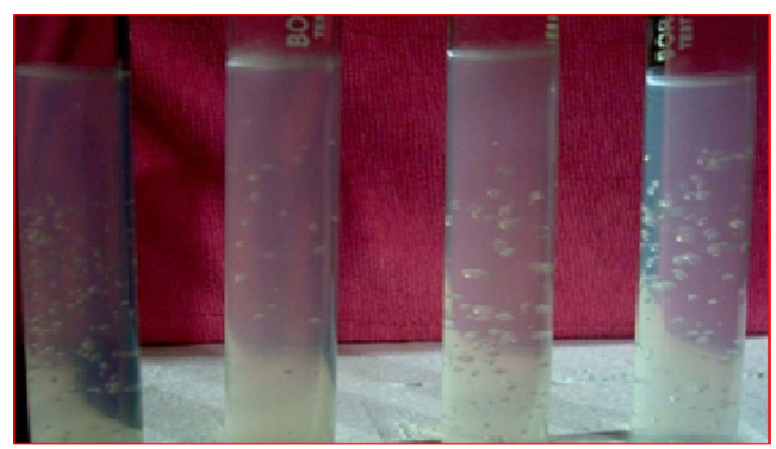

Figure 1. Struvite-k crystals with controlled nucleation in single diffusion.

Table1. Optimum condition for the growth of struvite-k crystals.

\begin{tabular}{ccc}
\hline Condition & Single diffusion & Double diffusion \\
\% of gel & 1.0 & 1.0 \\
Conc. of magnesium acetate & $1 \mathrm{M}$ \\
Conc. of KDP & 24 hours \\
Gel setting period & 48 hours \\
Gel aging & 60 days \\
Period of growth & Room temp. \\
Temperature & Translucents days \\
Quality & Platy, prismatic, star and polycrystalline \\
Shape & Opaque temp. \\
\hline
\end{tabular}




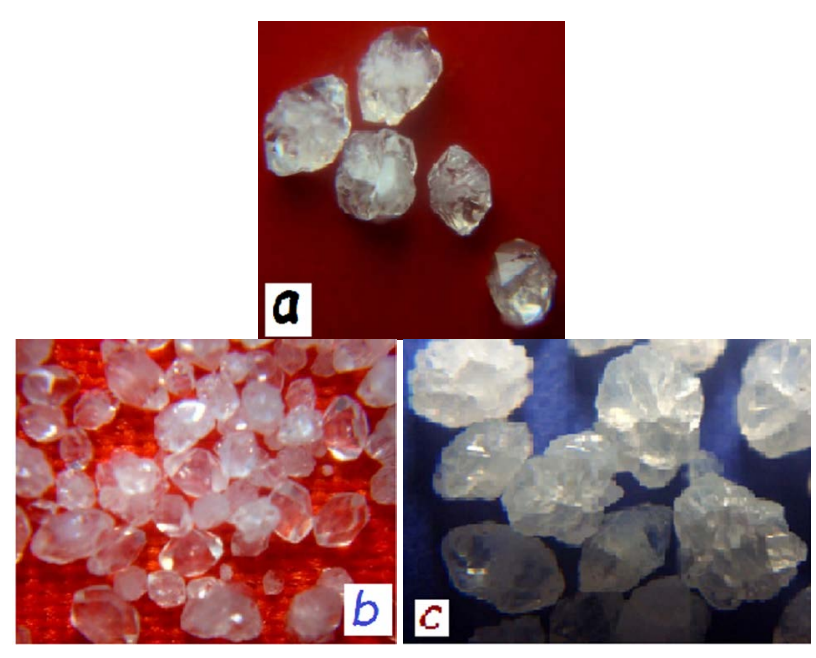

Figure 2. Struvite-k crystals in single diffusion. (a) Transparent star type; (b) Platy and prismatic type; (c) Polycrystalline type.

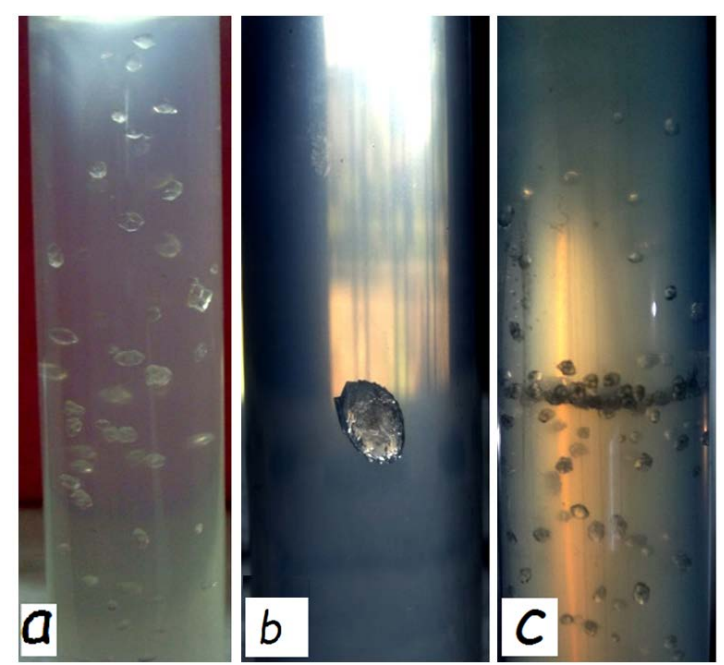

Figure 3. Growth of struvite-k crystal in single diffusion.

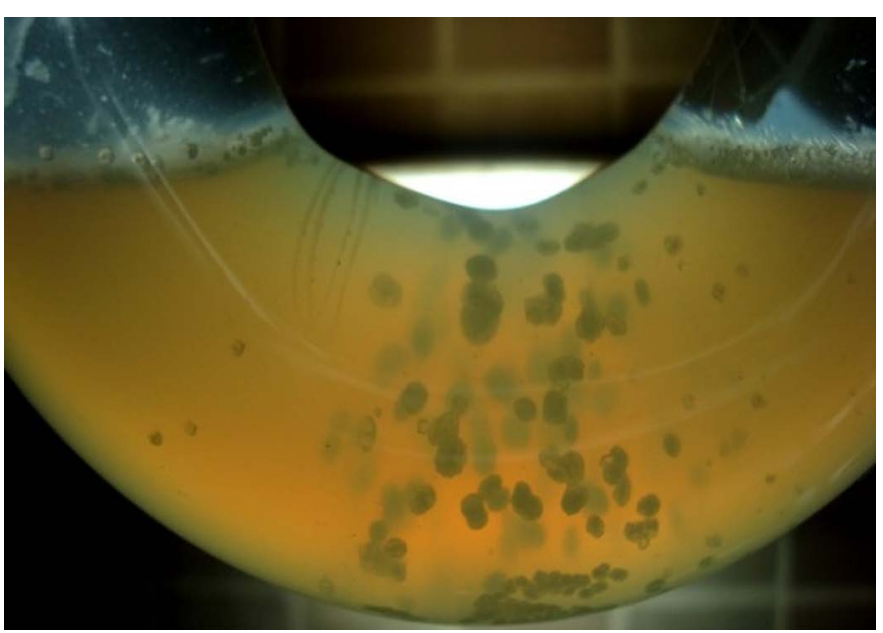

Figure 4. Growth of struvite-k crystal in double diffusion. 


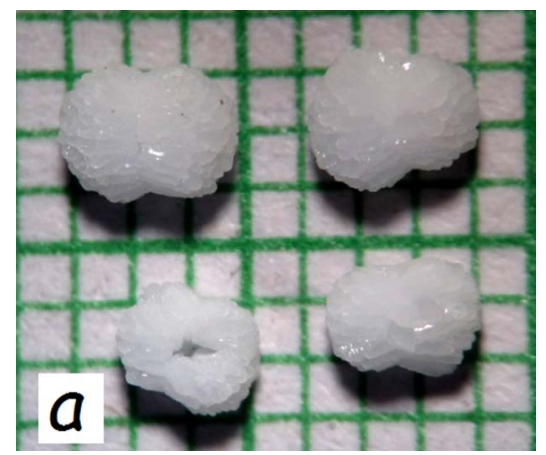

Figure 5. Opaque dumb-bell shape struvite-k crystals grown in double diffusion.

\subsection{Characterization}

\subsubsection{Optical Microscopy}

The microscopic photographs of struvite-k crystals shown in Figure 6 were observed under a CZM4 LABOMED stereo microscope. The morphology of the crystal is the result of the relative growth rates of its various faces. The crystal surfaces help to understand the mechanism and nature of crystals growth [38]. Figure 6(a), shows a semi-transparent crystal, with rough surface made up of peats and elongated as a rod in one side while a tip in other. However in Figure 6(b) an oval shaped crystal was observed, it's both the curvature are constant and the tips are in equal shape. The crystal is semi-transparent in multiple stepped pyramidal terminations and has multiple parallel prismatic faces on its upper surface.

In Figure 6(c), crystal was dendratic form and observed in triangular pyramidal edge shape. The center of the crystal was cloudy whereas the granular dendratic patterns were transparent. The shape of such crystal was due to entire composition of intergrown crystals.

Figure 6(d), shows the morphology of struvite-k crystals in double diffusion techniques. The grown crystal was in dumbbell shape having rounded ends and numbers of elliptical steps. This growth was due to the layer growth. The crystal layer ended on a rough surface composed of crystals with their points up and gave birth to a new layer of crystals arranged in a similar manner [39]. In double diffusion, the change in size and habits of the crystals were affected by the numerous parameters relating to reaction, viscosity of gel, diffusion of reactants and the solvent employed in gel [40].

\subsubsection{Scanning Electron Microscopy}

The morphology of struvite-k crystals was observed by using SEM as shown in Figures 7(a)-(c).

Figure 7(a) shows that the crystal was formed in elongated rectangular bar shaped morphology having with rough surface in an average particle size is $11.0 \times 2.0 \mu \mathrm{m}$. Both the ends of this micro crystal are flat. In Figure 7(b), the particle was observed in needle shape with flat surfaces. The length of this needle shaped micro crystal was approximately $8.8 \mu \mathrm{m}$. However the layer to layer morphology with an average size of $78.9 \times 39.0 \times 47.0$ $\mu \mathrm{m}$ was observed in Figure 7(c).These morphologies may be due to the fact that, the microcrystals were not growing in lateral direction, but also in particular thickness.

\subsubsection{FTIR Spectroscopic Analysis}

FTIR spectrum of the synthesized struvite-k crystal was recorded in the range of 400 to $4000 \mathrm{~cm}^{-1}$ is presented in Figure 8 and assigned vibrational band with observed wave numbers are summarized in Table 2.

The two broad IR bands located at $3514.42 \mathrm{~cm}^{-1}$ and $3275.24 \mathrm{~cm}^{-1}$ [21] are assigned to the H-O-H stretching vibrations of the water in crystals, while the two weak bands at $2478.61 \mathrm{~cm}^{-1}$ and $2393.74 \mathrm{~cm}^{-1}$ correspond to $\mathrm{H}-\mathrm{O}-\mathrm{H}$ stretching vibrations of cluster of water molecules in crystallization [22]. The medium intense bands appeared at $1699.34 \mathrm{~cm}^{-1}$ and $1653.05 \mathrm{~cm}^{-1}$ indicate the $\mathrm{H}-\mathrm{O}-\mathrm{H}$ bending modes of vibrations [41] [42], while a medium absorption band at $891.14 \mathrm{~cm}^{-1}$ indicates the wagging modes of vibration of the coordinated water and metal-oxygen bond in the complex [21].

In ideal case, free phosphate ion exhibits four fundamental modes of vibrations at $1082\left(v_{3}\right), 908\left(v_{1}\right), 515\left(v_{4}\right)$ and $363\left(v_{2}\right) \mathrm{cm}^{-1}$ [32]. Of these $v_{1}$ and $v_{3}$ are stretching, $v_{2}$ and $v_{4}$ are bending vibrations. In between these four 


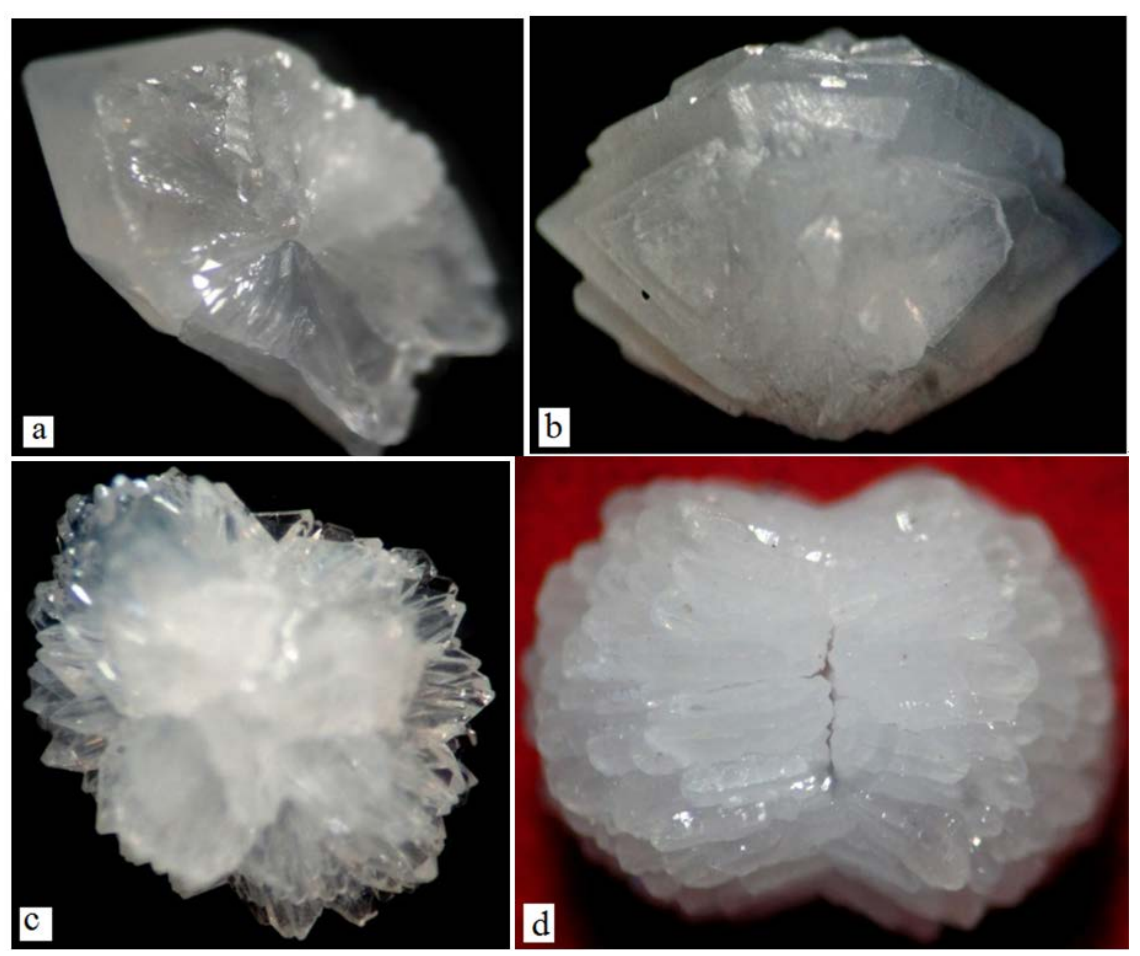

Figure 6. Stereoscope microscopy morphologies of struvite-k crystals. (a) Semitransparent with fine tip; (b) Translucent oval shape; (c) Milky star shaped; (d) Dumb-bell shaped crystals.

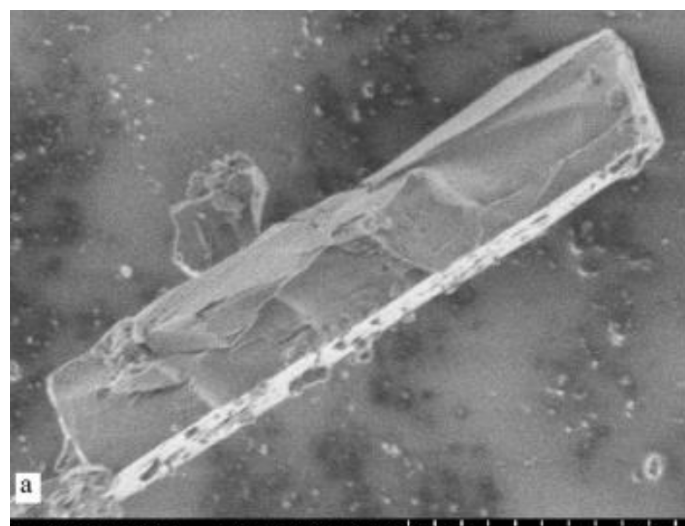

S-4800 1.0kV $9.8 \mathrm{~mm} \times 10.0 \mathrm{k} \mathrm{SE}(M) 2 / 8 / 2013$ 11:52

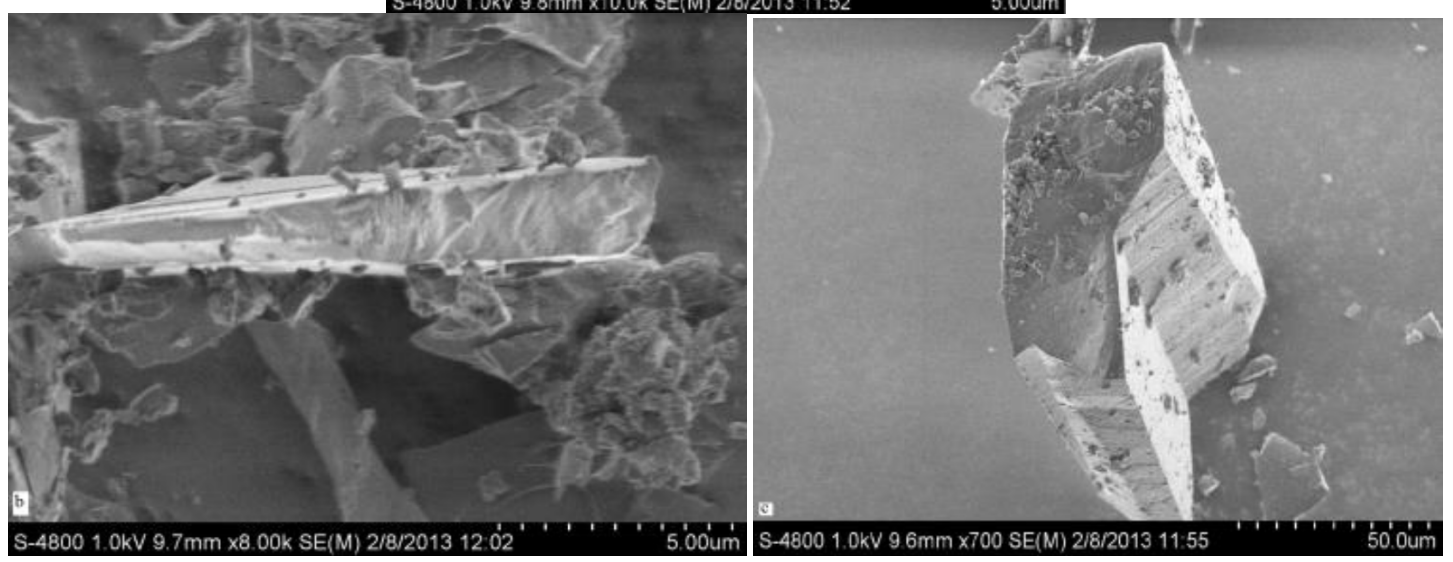

Figure 7. SEM of struvite-k crystals. 


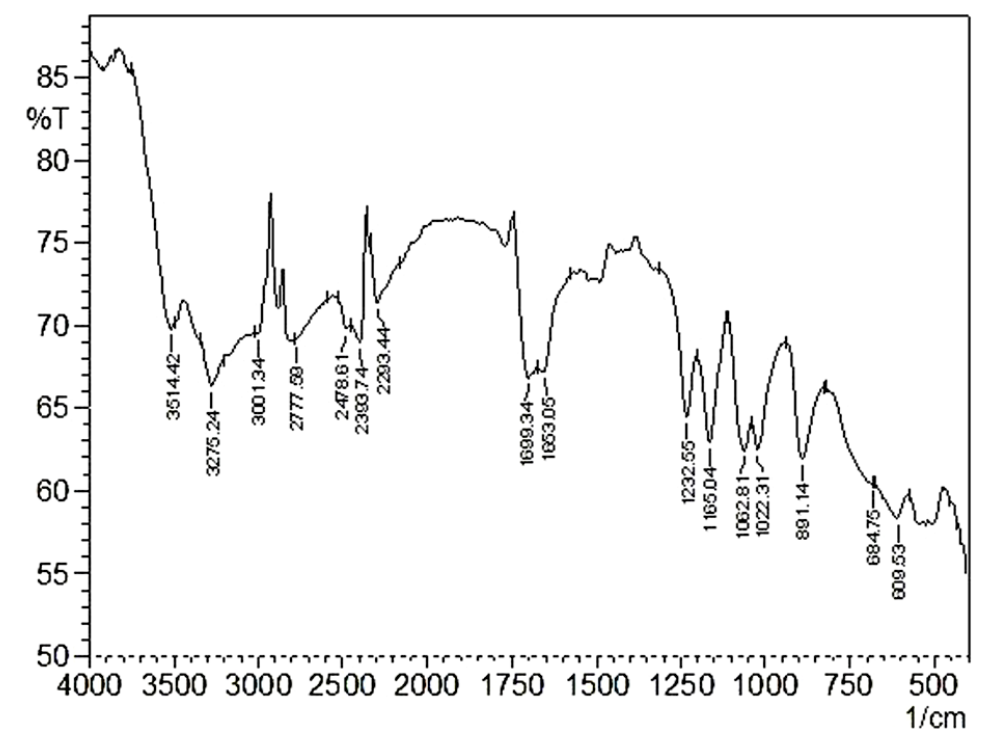

Figure 8. FTIR spectrum of struvite-k crystal.

Table 2. FTIR wave numbers and vibrations assignment of struvite-k crystals.

\begin{tabular}{|c|c|c|}
\hline Sr. No. & $\begin{array}{l}\text { Observed wave } \\
\text { numbers in } \mathrm{cm}^{-1}\end{array}$ & Bonds/Vibrational assignments \\
\hline 1 & 3514.42 & $\mathrm{H}-\mathrm{O}-\mathrm{H}$ stretching vibrations of water \\
\hline 2 & 3275.24 & $\mathrm{H}-\mathrm{O}-\mathrm{H}$ stretching vibrations of water \\
\hline 3 & 2478.61 & $\begin{array}{l}\mathrm{H}-\mathrm{O}-\mathrm{H} \text { stretching vibrations of cluster of water } \\
\text { molecules of crystallization }\end{array}$ \\
\hline 4 & 2393.74 & $\begin{array}{l}\mathrm{H}-\mathrm{O}-\mathrm{H} \text { stretching vibrations of cluster of water } \\
\text { molecules of crystallization }\end{array}$ \\
\hline 5 & 1699.34 & $\mathrm{H}-\mathrm{O}-\mathrm{H}$ bending modes of vibrations \\
\hline 6 & 1653.05 & $\mathrm{H}-\mathrm{O}-\mathrm{H}$ bending modes of vibrations \\
\hline 7 & 1232.55 & $v_{3}$ asymmetric stretching vibrations of $\mathrm{PO}_{4}$ \\
\hline 8 & 1165.04 & $v_{3}$ asymmetric stretching vibrations of $\mathrm{PO}_{4}$ \\
\hline 9 & 1062.81 & $v_{3}$ asymmetric stretching vibrations of $\mathrm{PO}_{4}$ \\
\hline 10 & 1022.31 & $v_{1}$ symmetric stretching vibrations of $\mathrm{PO}_{4}$ \\
\hline 11 & 891.14 & $\begin{array}{l}\text { Wagging modes of vibrations of coordinated } \\
\text { water }\end{array}$ \\
\hline 12 & 684.75 & Oxygen-metal bond \\
\hline
\end{tabular}

vibration modes only, $v_{3}$ and $v_{4}$ are infrared active [43]. In general, most of the phosphate ions are distorted from the ideal tetrahedral symmetry, but allow the non-active vibrations $v_{1}$ and $v_{2}$ to absorb energy in the infrared region [32]. In the present study, the band observed at $1022.31 \mathrm{~cm}^{-1}$ is attributed to $v_{1}$ symmetric stretching vibrations, whereas the bands at $1062.81 \mathrm{~cm}^{-1}, 1165.04 \mathrm{~cm}^{-1}$ and $1232.55 \mathrm{~cm}^{-1}$ are due to the $v_{3}$ asymmetric stretching vibrations of $\mathrm{PO}_{4}$ units in struvite-k crystals which correspond to previous reported values [21] [42] [44][46]. However, the peaks near the region $500 \mathrm{~cm}^{-1}$ correspond to the $v_{2}$ symmetric bending vibrations and $v_{4}$ asymmetric bending vibrations of $\mathrm{PO}_{4}$ units. A shoulder at $684.75 \mathrm{~cm}^{-1}$ indicates the presence of metal-oxygen bond [22] [41].

Thus, FTIR spectroscopy confirmed the growth of struvite-k crystals was due to the presence of water molecules, stretching and bending vibrations of phosphate $\left(\mathrm{PO}_{4}\right)$ ions and Mg-O bond. 


\subsubsection{X-Ray Analysis}

The XRD pattern of struvite-k crystal is shown in Figure 9. The crystalline phases and d-values obtained from the XRD have been compared with the JCPDS data. The XRD pattern of Figure 9 matches with the JCPDS files [47]-[49], indicating that the sample consisted of struvite-k crystalline.

The grain size is determined by measuring the width of the line with highest intensity peaks. The average grain size has been obtained from the XRD pattern using the Scherrer's formula [50], Grain size

$\mathrm{D}=0.94 \lambda / \beta \cdot \cos \theta$. Where $\beta$ is the full width at half maximum (FWHM) and $\lambda$ is the wave length of the X-rays. The obtained average grain size value is $87.3 \mathrm{~nm}$.

Table 3 gives the position, d-values and matching peaks of the struvite-k crystals and Figure 10 shows plot identified phases of struvite-k crystal.

\subsubsection{Energy Dispersive X-Ray Analysis (EDXA)}

The elemental composition of the sample is identified using energy dispersive X-ray analysis. The EDX spectrum of struvite-k crystal is shown in Figure 11. The higher peaks show the concentrated element as Mg, $\mathrm{P}$ and $\mathrm{O}$ in the specimen. Table 4 shows the EDX data of struvite-k crystals.

\subsubsection{Thermogravimetry (TGA)}

Chauhan et al. [21] and Siyu Zhang et al. [22] reported the dehydration characteristics of struvite-k crystals by TGA. In the present study, grown sample was also analyzed by TGA for thermal studies.

Figure 12 shows the thermogram of struvite-k crystals recorded in the temperature range $50^{\circ} \mathrm{C}-700^{\circ} \mathrm{C}$ at the rate of $10^{\circ} \mathrm{C} / \mathrm{min}$. The curve indicates that the mass loss is in one step i.e. dehydration of crystals and being started from $90^{\circ} \mathrm{C}$ and end at $600^{\circ} \mathrm{C}$. Up to this temperature, the mass of sample was found to be $63.11 \%$ of its original mass and then it remains stable up to $700^{\circ} \mathrm{C}$. This continuous loss of mass observed in TGA, corresponds to the dehydration of the struvite-k crystal. On the basis of TGA studies, the following tentative mechanism has been expected during the complete dehydration of struvite-k crystals.

$$
\mathrm{KMgPO}_{4} \cdot 6 \mathrm{H}_{2} \mathrm{O} \rightarrow \mathrm{KMgPO}_{4}+6 \mathrm{H}_{2} \mathrm{O} \uparrow
$$

The simultaneous loss of water molecules from the struvite-k structure may be taken as a function of temperature rather than in distinct steps [22]. In TGA study, the total mass loss is found to be $36.89 \%$, which is due to the loss of water in crystallization. Thus TGA study confirmed the structure of struvite-k crystals.

\section{Conclusions}

The struvite-k crystals are found to be grown by single and double diffusion techniques using agar gel as a medium of growth. Optical microscopy and SEM analysis show the growth mechanism and morphological properties of struvite-k crystals, such as star, platy, rectangular and prismatic obtained in single diffusion, while

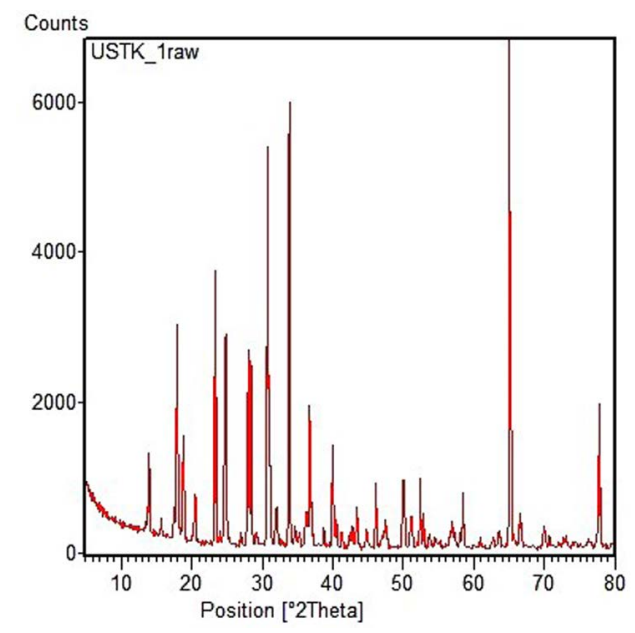

Figure 9. XRD pattern of Struvite-k crystal. 
Table 3. X-ray diffraction analysis of struvite-k crystals.

\begin{tabular}{|c|c|c|c|c|c|c|}
\hline Pos. $\left[{ }^{\circ} 2 \theta\right]$ & Height [cts] & FWHM $\left[{ }^{\circ} 2 \theta\right]$ & $\mathrm{d}$-spacing $\left[\mathrm{A}^{\circ}\right]$ & Rel. Int. [\%] & Tip width $\left[{ }^{\circ} 2 \theta\right]$ & Matched by \\
\hline 28.0096 & 2389.63 & 0.2160 & 3.18302 & 42.00 & 0.2592 & 35-0812; 1-075-1076; 20-06851 \\
\hline 28.4570 & 2115.93 & 0.1800 & 3.13398 & 37.19 & 0.2160 & 020-0685 \\
\hline 29.1873 & 286.19 & 0.2880 & 3.05720 & 5.03 & 0.3456 & 035-0812; 01-075-1076; 020-0685 \\
\hline 30.7676 & 3644.00 & 0.2160 & 2.90369 & 64.05 & 0.2592 & 035-0812; 01-075-1076; 020-0685 \\
\hline 31.1034 & 1270.55 & 0.1800 & 2.87310 & 22.33 & 0.2160 & 01-075-1076 \\
\hline 32.0585 & 603.90 & 0.1080 & 2.78965 & 10.61 & 0.1296 & 035-0812; 01-075-1076 \\
\hline 32.6944 & 182.52 & 0.2160 & 2.73682 & 3.21 & 0.2592 & 035-0812; 01-075-1076; 020-0685 \\
\hline 33.8161 & 5544.17 & 0.2160 & 2.64856 & 97.45 & 0.2592 & 035-081201-075-1076; 020-0685 \\
\hline 35.3186 & 232.92 & 0.3600 & 2.53926 & 4.09 & 0.4320 & 035-0812; 01-075-1076; 020-0685 \\
\hline 36.0231 & 318.82 & 0.2160 & 2.49119 & 5.60 & 0.2592 & 01-075-1076 \\
\hline 38.7514 & 282.99 & 0.2880 & 2.32185 & 4.97 & 0.3456 & 035-0812; 01-075-1076; 020-0685 \\
\hline 39.9202 & 1097.70 & 0.2880 & 2.25652 & 19.29 & 0.3456 & 035-0812; 01-075-1076 \\
\hline 42.7952 & 310.30 & 0.2160 & 2.11135 & 5.45 & 0.2592 & 035-0812; 01-075-1076; 020-0685 \\
\hline 43.4295 & 582.39 & 0.2520 & 2.08197 & 10.24 & 0.3024 & 01-075-1076 \\
\hline 44.7499 & 283.76 & 0.2880 & 2.02355 & 4.99 & 0.3456 & 035-0812; 01-075-1076 \\
\hline 46.1044 & 951.61 & 0.1440 & 1.96721 & 16.73 & 0.1728 & 035-081201-075-1076; 020-0685 \\
\hline 50.0247 & 942.53 & 0.1440 & 1.82184 & 16.57 & 0.1728 & 035-0812 \\
\hline 50.1438 & 994.07 & 0.1080 & 1.81779 & 17.47 & 0.1296 & 035-0812; 01-075-1076 \\
\hline 51.1517 & 484.85 & 0.1800 & 1.78432 & 8.52 & 0.2160 & 035-0812; 01-075-1076 \\
\hline 52.3372 & 979.30 & 0.0720 & 1.74665 & 17.21 & 0.0864 & 01-075-1076 \\
\hline 52.8762 & 527.85 & 0.1080 & 1.73011 & 9.28 & 0.1296 & 01-075-1076; 00-20-0685 \\
\hline 53.6568 & 246.28 & 0.2160 & 1.70677 & 4.33 & 0.2592 & 01-075-1076 \\
\hline 54.5191 & 190.84 & 0.2880 & 1.68180 & 3.35 & 0.3456 & 035-0812; 01-075-1076 \\
\hline 57.3198 & 250.49 & 0.2160 & 1.60610 & 4.40 & 0.2592 & 01-075-1076 \\
\hline 58.0061 & 270.98 & 0.1440 & 1.58872 & 4.76 & 0.1728 & 035-0812; 01-075-1076; 020-0685 \\
\hline 58.4651 & 578.77 & 0.2880 & 1.57733 & 10.17 & 0.3456 & 035-0812; 01-075-1076 \\
\hline 60.0389 & 111.75 & 0.4320 & 1.53969 & 1.96 & 0.5184 & 035-0812; 01-075-1076; 020-0685 \\
\hline 60.8746 & 185.71 & 0.2880 & 1.52054 & 3.26 & 0.3456 & 01-075-1076 \\
\hline 62.7481 & 198.02 & 0.2880 & 1.47957 & 3.48 & 0.3456 & 01-075-1076 \\
\hline 63.5173 & 290.15 & 0.2520 & 1.46349 & 5.10 & 0.3024 & 01-075-1076 \\
\hline 66.5280 & 432.19 & 0.1800 & 1.40438 & 7.60 & 0.2160 & 01-075-1076 \\
\hline 69.8674 & 326.00 & 0.2160 & 1.34520 & 5.73 & 0.2592 & 035-0812; 01-075-1076 \\
\hline 70.6214 & 247.25 & 0.1080 & 1.33267 & 4.35 & 0.1296 & 01-075-1076 \\
\hline 71.9566 & 147.83 & 0.2880 & 1.31120 & 2.60 & 0.3456 & 01-075-1076 \\
\hline 73.9686 & 143.61 & 0.2160 & 1.28043 & 2.52 & 0.2592 & 01-075-1076 \\
\hline 74.4110 & 154.98 & 0.4320 & 1.27390 & 2.72 & 0.5184 & 01-075-1076 \\
\hline 76.3870 & 148.20 & 0.7200 & 1.24579 & 2.60 & 0.8640 & 01-075-1076 \\
\hline 77.7426 & 2006.36 & 0.1080 & 1.22742 & 35.27 & 0.1296 & 01-075-1076 \\
\hline 77.9747 & 864.19 & 0.1080 & 1.22435 & 15.19 & 0.1296 & 01-075-1076 \\
\hline 79.5584 & 128.67 & 0.2160 & 1.20391 & 2.26 & 0.2592 & 01-075-1076 \\
\hline
\end{tabular}




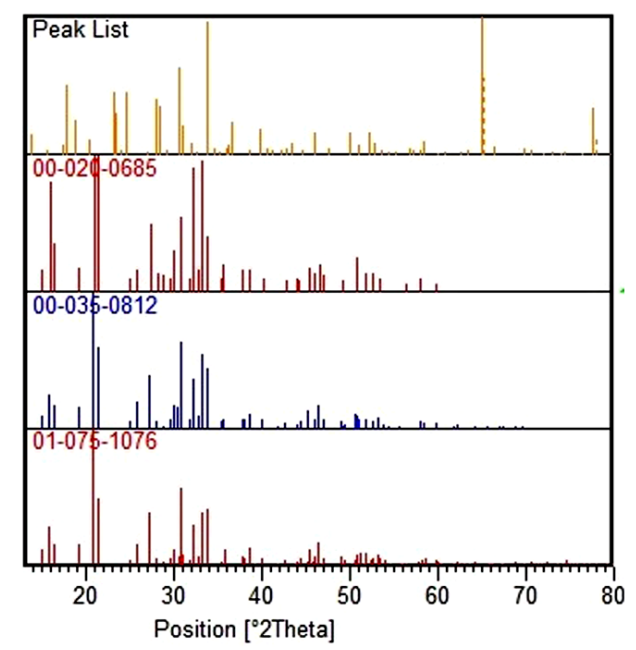

Figure 10. Plot of identified phases of struvite-k crystal.

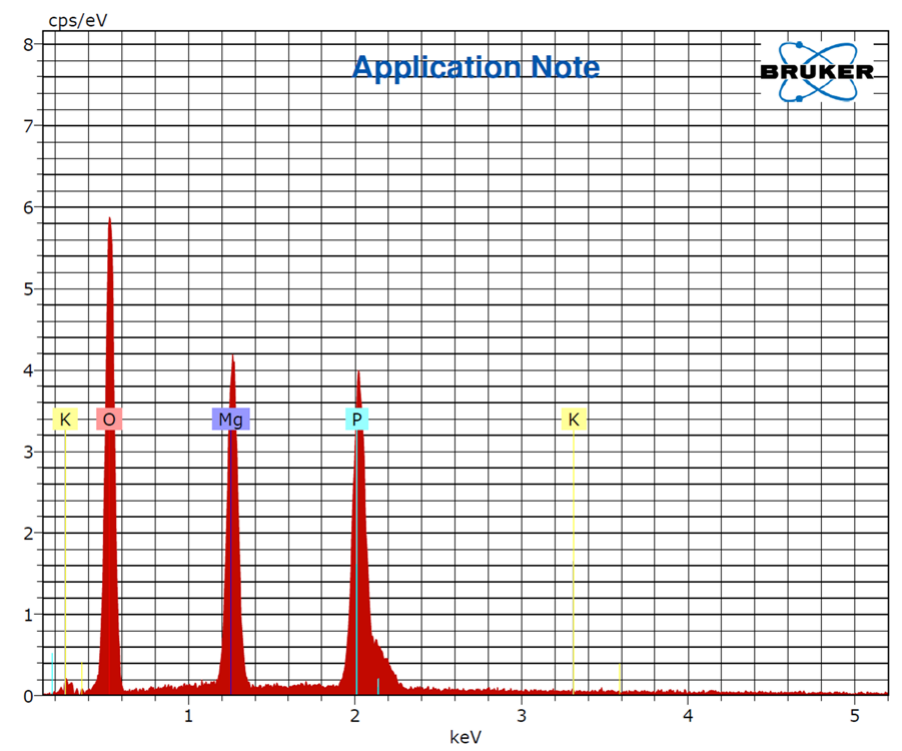

Figure 11. EDX spectrum of struvite-k crystal.

Table 4. EDX data of struvite-k crystals.

\begin{tabular}{ccccccc}
\hline El & AN & Series & Unn. C [wt. \%] & Norm. C. [wt. \%] & Atom. C [at. \%] & Error [wt. \%] \\
\hline O & 08 & k-series & 34.17 & 59.02 & 71.10 & 4.41 \\
Mg & 12 & k-series & 12.11 & 20.92 & 16.59 & 0.68 \\
P & 15 & k-series & 10.84 & 18.73 & 11.65 & 0.45 \\
K & 19 & k-series & 0.77 & 1.34 & 0.66 & 0.08 \\
& & Total & 57.89 & 100.00 & 100.00 & \\
\hline
\end{tabular}

dumbbell shape in double diffusion. FTIR spectroscopy reveals the various functional groups present in crystal. An X-ray diffraction pattern confirms the crystalline nature in the average grain size of 87.3 nm. EDXA leads to the conclusion that crystal shows the presence of magnesium, phosphor, carbon and oxygen. Whereas TGA study reveals that the one stage dehydration is due to loss of water. The proposed chemical formula and crystal structure for the grown sample is in good agreement with the results obtained from TGA studies. 


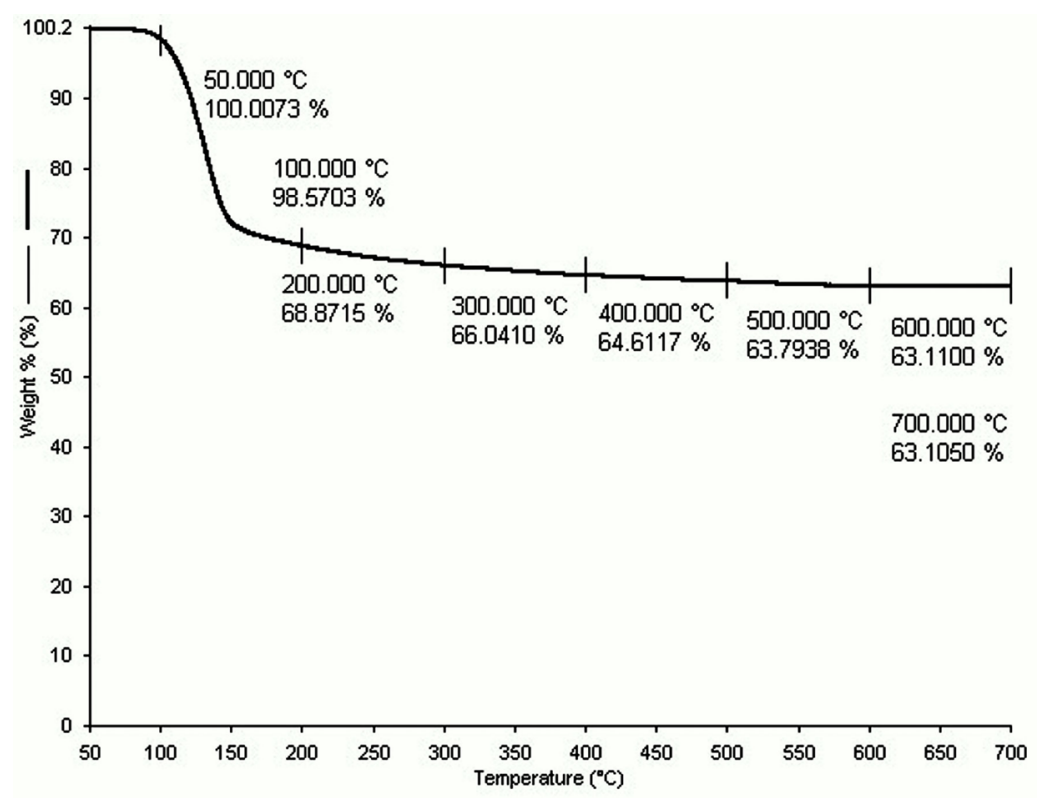

Figure 12. Thermogram of struvite-k crystal.

\section{Acknowledgements}

The authors are thankful to The Principal, Shri V. S. Naik Arts, Commerce and Science College, Raver (M.S.), to the Director, UDCT, NMU, Jalgaon and to the Director, SICART (Gujarat) for providing experimental facilities.

\section{References}

[1] Chauhan, C.K. and Joshi, M.J. (2013) In Vitro Crystallization, Characterization and Growth-Inhibition Study of Urinary Type Struvite Crystals. Journal of Crystal Growth, 362, 330-337. http://dx.doi.org/10.1016/j.jcrysgro.2011.11.008

[2] Lingeman, J., Kahnoski, R., Mardis, H., Goldfarb, D.S., Grasso, M., Lacy, S., Scheinman, S.J., Asplin, J.R., Parks, J.H. and Coe, F.L. (1999) Divergence between Stone Composition and Urine Saturation: Clinical and Biological Implication. Journal of Urology, 161, 1077-1081. http://dx.doi.org/10.1016/s0022-5347(01)61594-5

[3] Zarasvandi, A., Heidari, M., Sadeghi, M. and Mousapoor (2013) Major and Trace Element Composition of Urinary Stones, Khuzestan Province, Southwest, Iran. Journal of Geochemistry Exploration, 131, 52-58. http://dx.doi.org/10.1016/j.gexplo.2012.08.014

[4] Kumar, N., Singh, P. and Kumar, S. (2006) Physical, X-Ray Diffraction and Scanning Electron Microscopic Studies of Uroliths. Indian Journal of Biochemistry\& Biophysics, 43, 226-232.

[5] Diana, K.J. and George, K.V. (2013) Urinary Stone Formation: Efficacy of Seed Extract of Ensetesuperbum (Roxb.) Cheesman on Growth Inhibition of Calcium Hydrogen Phosphatedihydrate Crystals. Journal of Crystal Growth, 363, 164-170. http://dx.doi.org/10.1016/j.jcrysgro.2012.10.036.

[6] Parekh, B., Joshi, M. and Vaidya, A. (2008) Characterization and Inhibitive Study of Gel-Grown Hydroxyapatite Crystals at Physiological Temperature. Journal of Crystal Growth, 310, 1749-1753. http://dx.doi.org/10.1016/j.jcrysgro.2007.11.219

[7] Menon, M., Parulkar, B.G. and Drach, G.W. (1998) Urinary Lithiasis: Etiology, Diagnosis and Medical Management, Campbell's Urology, 3, 2661-2733.

[8] Joshi, V.S. and Joshi, M.J. (2003) FTIR Spectroscopic, Thermal and Growth Morphological Studies of Calcium Hydrogen Phosphate Dihydrate Crystals. Crystal Research Technology, 38, 817-821.

http://dx.doi.org/ 10.1002/crat.200310100

[9] Abbona, F. and Boistelle, R. (1979) Growth Morphology and Crystal Habit of Struvite Crystals $\left(\mathrm{MgNH}_{4} \mathrm{PO}_{4} \cdot 6 \mathrm{H}_{2} \mathrm{O}\right)$. Journal of Crystal Growth, 46, 339-354. http://dx.doi.org/10.1016/0022-0248(79)90082-4

[10] Daeshner, C.W., Singleton, E.B. and Curtis, J.C. (1960) Urinary Tract Calculi and Nephrocalcinosis in Infants and Children. Journal of Pediatrics, 57-5, 721-732. http://dx.doi.org/ 10.1016/s0022-3476(60)80166-7 
[11] Sun, X., Shen, L., Cong, X., Zhu, H., Lv, J.L. and He, L. (2011) Infrared Spectroscopic Analysis of Urinary Stones (Including Stones Induced by Melamine-Contaminated Milk Powder) in 189 Chinese Children. Journal of Pediatric Surgery, 46, 723-728. http://dx.doi.org/10.1016/j.jpedsurg.2010.09.013

[12] Alpay, H., Ozen, A., Gokee, I. and Biyikli, N. (2009) Clinical and Metabolic Features of Urolithiasis and Microlithiasis in Children. Pediatric Nephrology, 24, 2203-2209. http://dx.doi.org/ 10.1007/s00467-009-1231-9

[13] Shah, A.M., Kalmunkar, S., Punekar, S.V., Billimoria, F.R., Bapat, S.D. and Deshmukh, S.S. (1991) Spectrum of Pediatric Urolithiasis in Western India. Indian Journal of Pediatrics, 58, 543-549. http://dx.doi.org/10.1007/BF02750939

[14] Lonsdale, K. and Sutor, D.J. (1966) Newberyite in Ancient and Modern Urinary Calculi: Identification and Space Group. Science, 154, 1353-1354. http://dx.doi.org/10.1126/science.154.3754.1353

[15] Chauhan, C.K., Joshi, M.J. and Vaidya, A.D.B.J. (2009) Growth Inhibition of Struvite Crystals in the Presence of Herbal Extract Commiphora wightii. Journal of Materials Science: Materials in Medicine, 20, 85-92. http://dx.doi.org/10.1007/s10856-008-3489-z

[16] Jacobs, D., Heimbach, D. and Hesse, A. (2001) Chemolysis of Struvite Stones by Acidification of Artificial Urine-An in Vitro Study. Scandinavian Journal of Urology \& Nephrology, 35, 345-349. http://dx.doi.org/10.1080/003655901753224387

[17] Hesse, A. and Heimbach, D. (1999) Causes of Phosphate Stone Formation and the Importance of Metaphylaxis by Urinary Acidification: A Review. World Journal of Urology, 17, 308-315. http://dx.doi.org/10.1007/s003450050152

[18] Babic-Ivancic, V., Kontrec, J. and Brecevic, L. (2004) Formation and Transformation of Struvite and Newberyite in Aqueous Solutions under Conditions Similar to Physiological. Urological Research, 32, 350-356. http://dx.doi.org/10.1007/s00240-004-0427-5

[19] Banks, E., Chianelli, R. and Korenstein, R. (1975) Crystal Chemistry of Struvite Analogs of the Type $\mathrm{MgMPO}_{4} \cdot 6 \mathrm{H}_{2} \mathrm{O}$ $\left(\mathrm{M}+=\mathrm{K}+, \mathrm{Rb}+, \mathrm{Cs}+, \mathrm{T}^{1+}, \mathrm{NH}^{4+}\right) 1$. Inorganic Chemistry, 14, 1634-1639. http://dx.doi.org/10.1021/ic50149a041

[20] Ravikumar, R.V.S.S.N., Chandrasekhar, A.V., Rao, S.N., Madhu, N., Reddy, B.J. and Reddy, Y.P. (1999) Orthorhombic Site Symmetry of $\mathrm{Cr}^{3+}$ in $\mathrm{ZnNH}_{4} \mathrm{PO}_{4} \cdot 6 \mathrm{H}_{2} \mathrm{O}$ Crystals. Crystal Research and Technology, 34, 911-914. http://dx.doi.org/10.1002/(SICI)1521-4079(199908)34:7<911::AID-CRAT911>3.0.CO;2-B

[21] Chauhan, C.K., Vyas, P.M. and Joshi, M.J. (2011) Growth and Characterization of Struvite-K Crystals. Crystal Research and Technology, 46, 187-194. http://dx.doi.org/10.1002/crat.201000587

[22] Zhang, S., Shi, H.S., Huang, S.W. and Zhang, P. (2013) Dehydration Characteristics of Struvite-K Pertaining to Magnesium Potassium Phosphate Cement System in Non-Isothermal Condition. Journal of Thermal Analysis and Calorimetry, 111, 35-40. http://dx.doi.org/10.1007/s10973-011-2170-9

[23] Sun, W.D., Wang, J.Y., Zhang, K.C. and Wang, X.L. (2010) Study on Precipitation of Struvite and Struvite-K Crystal in Goats during Onset of Urolithiasis. Research in Veterinary Science, 88, 461-466. http://dx.doi.org/10.1016/j.rvsc.2009.11.010

[24] Graeser, S., Postl, W., Bojar, H.P., Berlepsch, P., Armbruster, T., Raber, T., Ettinger, K. and Walter, F. (2008) Struvite-(K), $\mathrm{KMgPO}_{4} \cdot 6 \mathrm{H}_{2} \mathrm{O}$, the Potassium Equivalent of Struvite-A New Mineral. European Journal of Mineral, 20 , 629-633.

[25] Wang, X.L., Huang, K.H., Gao, J.B., Shen, X.Z., Lin, C.Y. and Zhang, G.D. (1997) Chemical Composition and Microstructure of Uroliths and Urinary Sediment Crystals Associated with the Feeding of High-Level Cottonseed Meal Diet to Water Buffalo Calves. Research in Veterinary Science, 62, 275-280. http://dx.doi.org/10.1016/S0034-5288(97)90204-6

[26] Dunlevey, J. and Laing, M. (2008) Struvite Infection Calculi in Dogs: Problems with Urinary Calculus Identification, and the Value of the Results. South African Journal of Science, 104, 471-472.

http://dx.doi.org/10.1590/S0038-23532008000600021

[27] Patel, A.R. and Rao, A.V. (1982) Crystal Growth in Gel Media. Bulletin of Materials Science, 4, 527-548. http://dx.doi.org/10.1007/BF02824961

[28] Shivkumar, G.R., Girija, E.K., Kalkura, S.N. and Subramanian, C. (1998) Crystallization and Characterization of Calcium Phosphates: Brushite and Monetite. Crystal Research and Technology, 33, 197-205. http://dx.doi.org/10.1002/(SICI)1521-4079(1998)33:2<197::AID-CRAT197>3.0.CO;2-K

[29] Ouyang, J., Deng, S., Li, X., Tan, Y. and Bernd, T. (2004) Effects of Temperature and Sodium Carboxylate Additives on Mineralization of Calcium Oxalate in Silica Gel Systems. Science in China Series B, Chemistry, 47, 311-319. http://dx.doi.org/10.1360/03yb0027

[30] Bretherton, T. and Rodgers, A. (1998) Crystallization of Calcium Oxalate in Minimally Diluted Urine. Journal of Crystal Growth, 192, 448-455. http://dx.doi.org/10.1016/s0022-0248(98)00461-8 
[31] Heferburg, G., Kloess, G., Schmitz, W. and Kothe, E. (2008) “Ni-Struvite”-A New Biomineral Formed by a Nickel Resistant Streptomyces Acidiscabies. Chemosphere, 72, 517-523. http://libgen.org/scimag4/10.1016/j.chemosphere.2008.02.050 http://dx.doi.org/10.1016/j.chemosphere.2008.02.050

[32] Ravikumar, R.V.S.S.N., Chandrasekhar, A.V., Ramakrishna, C.H. and Reddy, Y.P. (2001) Structural and Spectral Studies of $\mathrm{ZnKPO}_{4} \cdot 6 \mathrm{H}_{2} \mathrm{O}$ Crystals. Crystal Research and Technology, 36, 1429-1433. http://dx.doi.org/10.1002/1521-4079(200112)36:12<1429::AID-CRAT1429>3.0.CO;2-W

[33] Henisch, H.K. (1988) Crystals in Gels and Liesegang Rings. Cambridge University Press, Cambridge. http://dx.doi.org/10.1017/CBO9780511525223

[34] Bhavsar, D.S. (2012) Effect of Various Parameters to Grow Lead Iodide Crystals Grown by Gel Method. Archives of Physics Research, 3, 146-148.

[35] Patil, S.N. and Venkateswara Rao, A. (1991) Effect of Gel Parameters on Nucleation and Growth of $\mathrm{CaSO}_{3} \cdot 0.5 \mathrm{H}_{2} \mathrm{O}$ Crystals in Silica Gel. Crystal Research and Technology, 26, 847-853. http://dx.doi.org/10.1002/crat.2170260707

[36] Dalal, P.V. and Saraf, K.B. (2011) Growth of Strontium Oxalate Crystals in Agar-Agar Gel. Bulletin of Materials Science, 34, 377-381. http://libgen.org/scimag2/10.1007/s12034-011-0080-x.pdf http://dx.doi.org/10.1007/s12034-011-0080-x

[37] Bisaillon, S. and Tawashi, R. (1975) Growth of Calcium Oxalate in Gel Systems. Journal of Pharmaceutical Sciences, 64, 458-460. http://dx.doi.org/10.1002/jps.2600640325

[38] Yellin, Z.B., Mil, J.V., Addadi, L., Idelson, M., Lahav, M. and Leiserowitz, L. (1985) Crystal Morphology Engineering by “Tailor-Made” Inhibitors: A New Probe to Fine Intermolecular Interactions. Journal of the American Chemical Society, 107, 3111-3122. http://dx.doi.org/10.1021/ja00297a017

[39] Millan, A. (1997) Crystal Morphology and Texture in Calcium Oxalate Monohydrate Renal Calculi. Journal of Materials Science: Materials in Medicine, 8, 247-250. http://libgen.org/scimag3/10.1023/a\%253A1018547909119.pdf

[40] Yaghi, O.M., Li, G.M. and Li, H.L. (1997) Crystal Growth of Extended Solids by Non-Aqueous Gel Diffusion. Chemistry of Materials, 9, 1074-1076. http://dx.doi.org/ 10.1021/cm970069e

[41] Dalal, P.V., Saraf, K.B. and Shah, S. (2009) Growth of Barium Oxalate Crystals in Agar-Agar Gel and Their Characterization. Crystal Research and Technology, 44, 36-42. http://dx.doi.org/10.1002/crat.200800221

[42] Fost, R.L., Xi, Y., Scholz, R., Belotti, F.M. and Filho, M.C. (2013) The Phosphate Mineral Sigloite $\mathrm{Fe}^{3+} \mathrm{Al}_{2}$ $\left(\mathrm{PO}_{4}\right)_{2}(\mathrm{OH})_{3} \cdot 7\left(\mathrm{H}_{2} \mathrm{O}\right)$, an Exception to the Paragenesis Rule-A Vibrational Spectroscopic Study. Journal of Molecular Structure, 1033, 258-264. http://dx.doi.org/10.1016/j.molstruc.2012.10.020

[43] Fost, R.L., Palmer, S., Xi, Y., Cejka, J., Sejkora, J. and Plasil, J. (2013) Raman Spectroscopic Study of the HydroxyPhosphate Mineral Plumbogummite $\mathrm{PbAl}_{3}\left(\mathrm{PO}_{4}\right)_{2}\left(\mathrm{OH}, \mathrm{H}_{2} \mathrm{O}\right)_{6}$. Spectrochimica Acta Part A: Molecular and Biomolecular Spectroscopy, 103, 431-434. http://dx.doi.org/10.1016/j.saa.2012.07.057

[44] Fost, R.L., Cejka, J., Weier, M. and Martens, W.N. (2006) A Raman Spectroscopic Study of the Uranyl Phosphate Mineral Parsonsite. Journal of Raman Spectroscopy, 37, 879-891. http://dx.doi.org/10.1002/jrs.1517

[45] Fost, R.L. and Palmer, S.J. (2007) A Raman Spectroscopic Study of the Phosphate Mineral Pyromorphite $\mathrm{Pb}_{5}\left(\mathrm{PO}_{4}\right)_{3} \mathrm{Cl}$. Polyhedron, 26, 4533-4541. http://dx.doi.org/10.1016/j.poly.2007.06.004

[46] Reddy, B.J., Fost, R.L. and Palmer, S.J. (2007) A Near-Infrared Spectroscopic Study of the Phosphate Mineral Pyromorphite $\mathrm{Pb}_{5}\left(\mathrm{PO}_{4}\right)_{3}$ Cl. Spectrochimica Acta Part A, 71, 430-435. http://dx.doi.org/10.1016/j.saa.2007.12.030

[47] Joint Committee for Powder Diffraction Standards Reference Card Number 35-0812.

[48] Joint Committee for Powder Diffraction Standards Reference Card Number 01-075-1076.

[49] Joint Committee for Powder Diffraction Standards Reference Card Number 20-0685.

[50] Maleki, M., Ghamsari, M.S., Mirdamadi, Sh. and Ghasemzadeh, R. (2007) A Facile Route for Preparation of CdS Nanoparticles. Semiconductor Physics, Quantum Electronics \& Optoelectronics, 10, 30-32. 
Scientific Research Publishing (SCIRP) is one of the largest Open Access journal publishers. It is currently publishing more than 200 open access, online, peer-reviewed journals covering a wide range of academic disciplines. SCIRP serves the worldwide academic communities and contributes to the progress and application of science with its publication.

Other selected journals from SCIRP are listed as below. Submit your manuscript to us via either submit@scirp.org or Online Submission Portal.
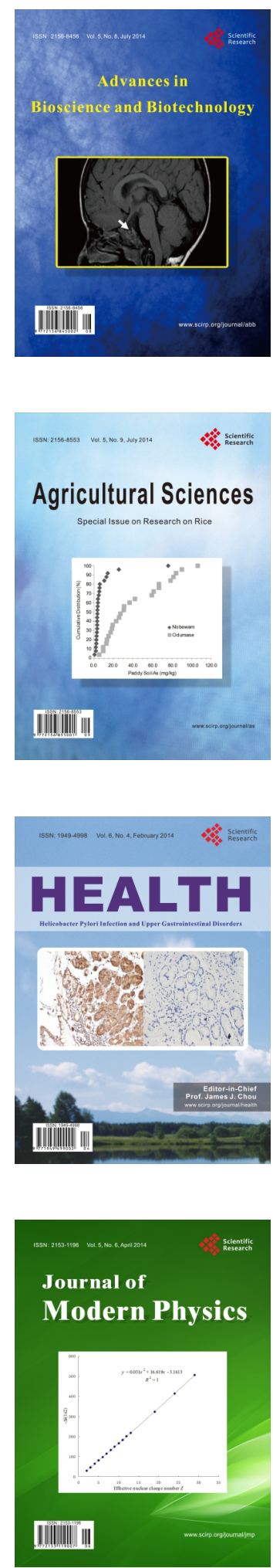
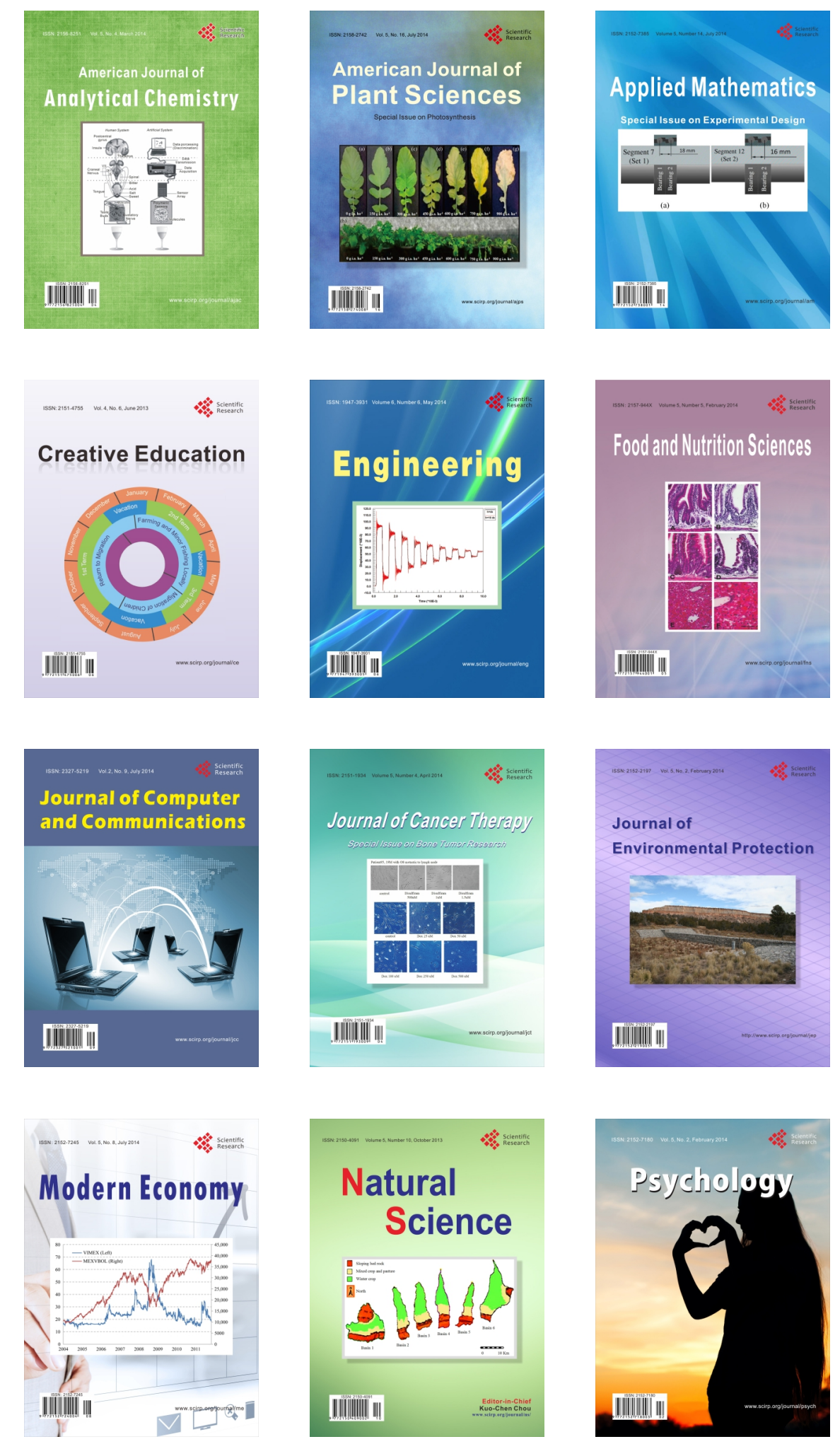